إدارة المعرفة وإمكانية تطبيقها وسبل تطويرها:

دراسة حالة المكتبة المركزية في جامعة المانية السليمانية

المدرس سينــاء شمهـال

الجامعة المستنصرية / كليـة الآداب - قسم المعلومات لماء والمكتبات

susus47@yahoo.com

\begin{abstract}
الملخص:
يرمي البحث إلى تثخيص واقع ،ادارة المعرفة في المكتبة المركزية بجامعة السليمانية، والتعرف على مستوى

الوعي لإدارة المعرفة لدى العاملين في المكتبة. اتبعت الباحثة المنهج الوثائقي في الجانب، النظري ومنهج دراسة

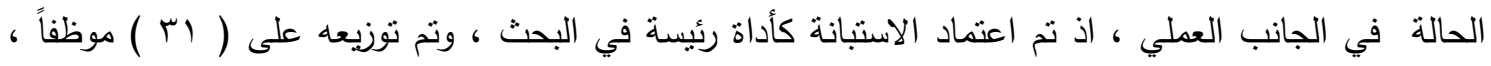

وخرجت الدراسة بنتائج متعددة اهمها:

1 ـ عدم توافر جهة مسؤولة تعنى بالإثراف على إدارة المعرفة وتتفيذ عملياتها ، اذ شكلت نسبة (7 (1\%) ـ

r. يعدُ التدريب من أبرز سبل تطوير نطبيق إدارة المعرفة في المكتبة من وجهة نظر العاملين من خلال اشتراكهر

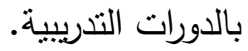

الكلمات المفتاحية: إدارة المعرفة، جامعة السليمانية، تكنولوجيا المعلومات.
\end{abstract}

\title{
Cognitive management and the possibility of its application and development: A case study of the central library in Mustansiriya
}

\section{University}

Inst. sienaa shimal

\section{Mustansiriya University /College of arts / Al - Department of Information and Libraries}

\begin{abstract}
:
The research aims to diagnose the reality of cognitive Management in the Central Library at the University of Sulaymaniyah, and to identify the level of awareness for the management of knowledge among workers in the library. The researcher followed the documentary approach in the theoretical side and the case study method in the practical side, as has been the adoption of the questionnaire as a key tool in the search was distributed on (31) employees exited the study results of several most important:

1. The lack of a responsible party means to oversee operations and knowledge management accounting (16\%) .

2. The training is the most prominent ways to develop the application of knowledge management in the library from the perspective of employees through their participation in training courses.
\end{abstract}

Keywords: Cognitive Management, University of Sulaymaniyah, Information technology. 


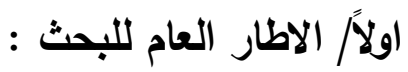

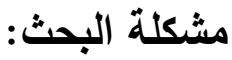

إن نجاح أية مؤسسة يعتمد على مدى مواكبة إدارتها لكل ما هو جديد، فضلاً عن قدرتها و

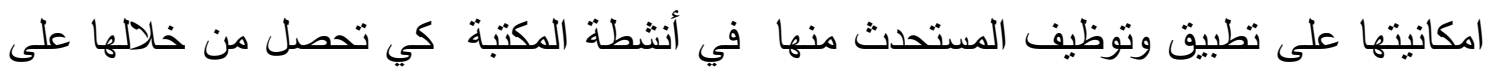
بقائها ، نموها، ووصولها الى مراكز متقدمة في الخدمات والابداع، و على الرغم من ذللك لحظت فئه

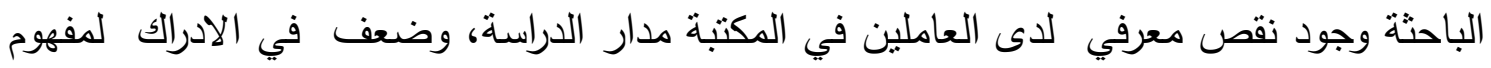

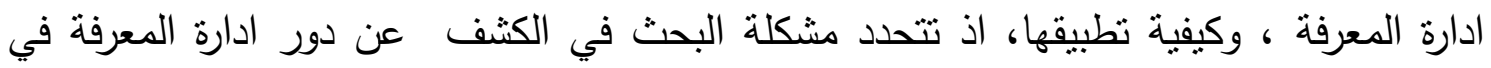

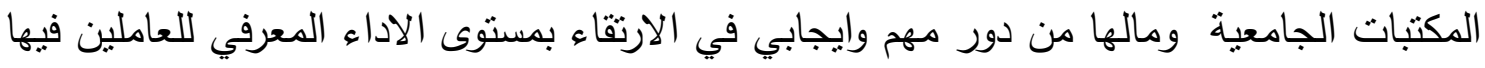
نحو الافضل وذلك من خلال الاجابة عن التساؤلات الاتية:

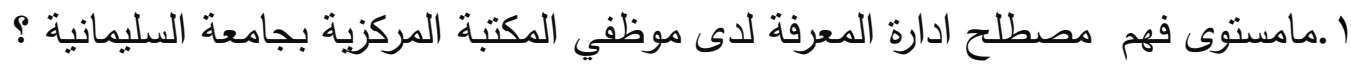

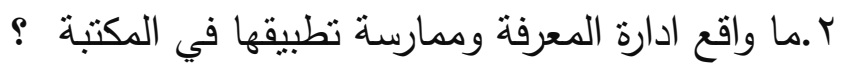
r.ما ابرز المشكلات والصعوبات التي تواجهها المكتبة في تطبيق ادارة المعرفة ؟ ـ ـما سبل تطوير تطبيق إدارة المعرفة في المكتبة المركزية لجامعة السليمانية ؟

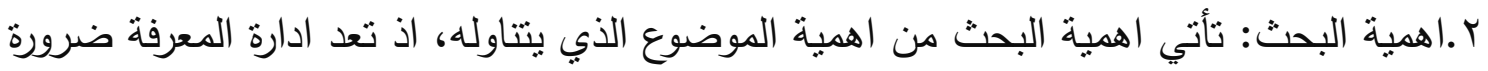

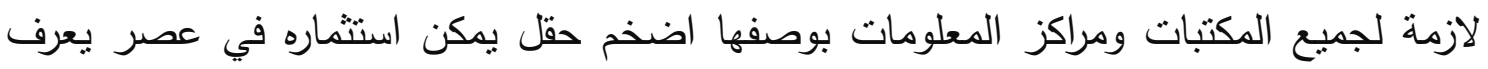
باقتصاد المعرفة. اذ جاءت هذه الدراسة لتساعد ادارة الدكتبة عن ادراك مفهوم ادارة المعرفة ، وفهم

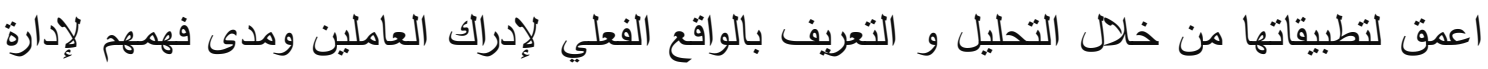

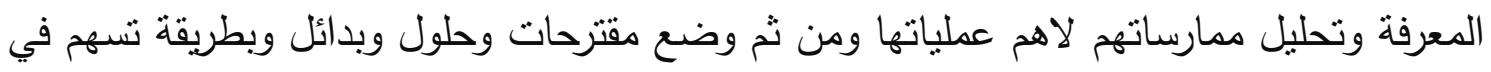
تحقيق اهداف المكتبة ، وخدمة المجتمع الجامعي في ظل البئي البئة المعرفية .

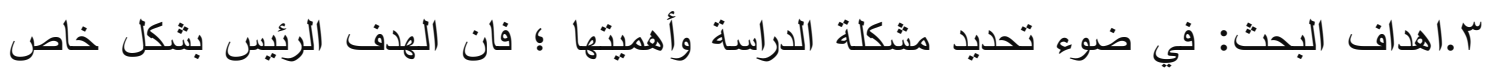
يتمثل في التعرف بواقع ادارة المعرفة في المكتبة المركزية بجامعة السليمانية، وبشكل عام يمكن

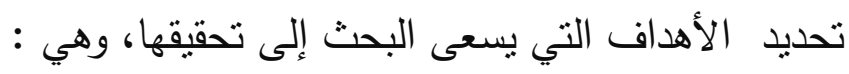
ا ـ ـتخيص الواقع الحالي للمكتبة المركزية بجامعة السليمانية. r. ب.التعرف على مسنوى الوعي لإدارة المعرفة لدى العاملين في المكتبة. r. بيان واقع ادارة المعرفة، وممارسة تطبيقها في المكتبة. ع .تتخيص المشكلات و المعوقات التي تواجه ادارة المكتبة لتطبيق ادارة المعرفة وممارستها. 0.معرفة سبل تطوير تطبيق إدارة المعرفة في المكتبة المركزية لجامعة السليمانية.

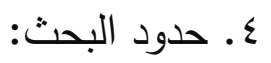

أ. الحدود المكانية: يقتصر البحث على المكتبة المركزية بجامعة السليمانية . 


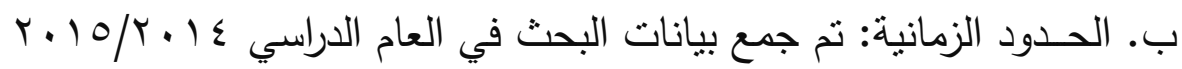

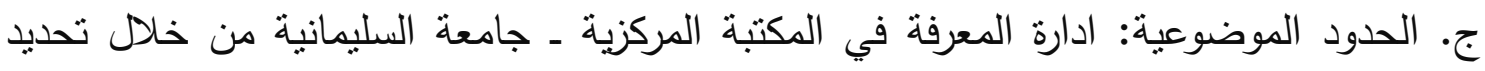
مفهوم ادارة المعرفة كما يدركها العاملون، وتحديد ممارستهم لها.

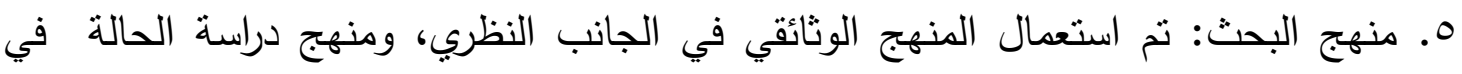
الجانب العملي ، اذ نم اتباع اسلوب استطلاع آراء العاملين في المكتبة المركزية بجامعة

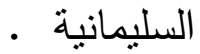

7. مجتمع البحث: حددت الباحثة مجتمع الدراسة على أن يتكون من جميع العاملين (ممن

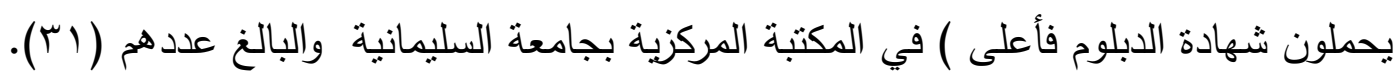

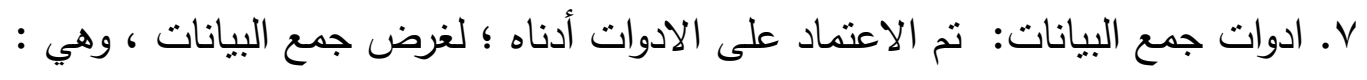

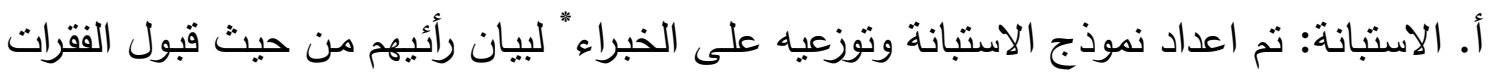

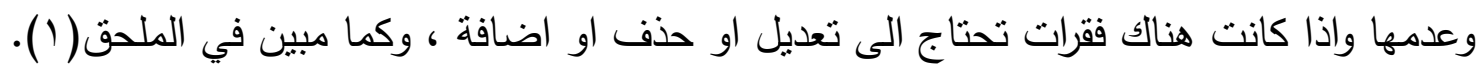

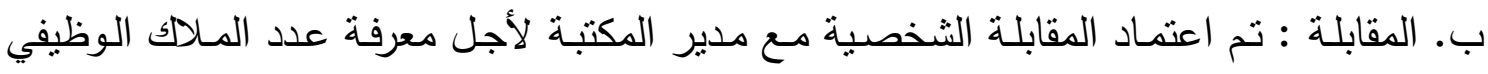

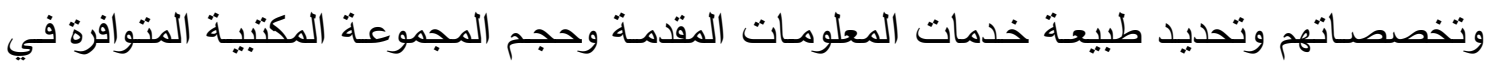

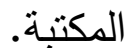

ج. الملاحظة: نم اعتماد الملاحظة للتأكد من ضمان ومصداقية الإجابة عن أسئلة الاستبانة د. الوثائق والسجلات: تم الاعتماد على السجلات والوثائق الرسمية للمكتبة وفهارسها والمصادر العلمية التي تحتويها ^. الدراسات السـابقة: نعيمة حسن جبر رزوقي (()). رؤية مستقبلية لدور اختصاصيبي المعلومات

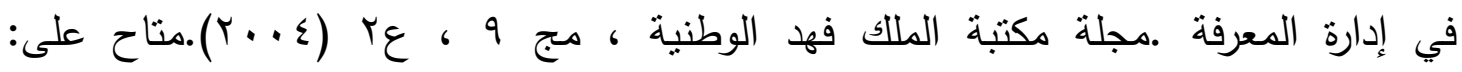
http://alyaseer.net

ترمي الورقة التعريف بالمعرفة المطلوب إدارتها وأنواعها كما تبين عمليات إدارة المعرفة

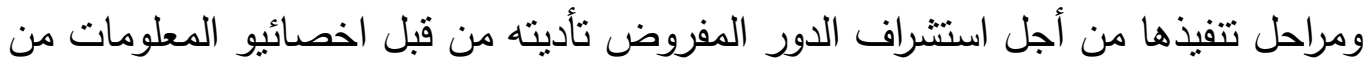
المهارات المطلوب اكتسابها للعمل ضمن فريق إدارة المعرفة .

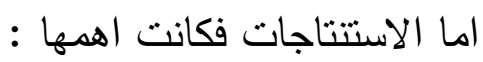
أن الإثكال لا يكمن فيما يقوم به اختصاصيب المعلومات من عمليات أو ما ينجزه في مراحل، إنما الإثكال يقع في نوع المعرفة التي يديرها. فهو ناجح في إدارة الدعرفة الصريحة وينجح في إدارة 
المعرفة الضمنية بعد تحويلها إلى معرفة صريحة ولكن ييقى دوره غير واضح في عملية التحويل وهي بؤرة العمل الحالي لإدارة المعرفة في أية مؤسسة كانت خدمية أو إنتاجية أو تعليمية.

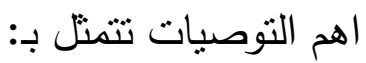

1. التأكبد على ورش العمل والدورات التنريبية لمديري المؤسسات لتوعيتهم بدور اختصاصيي

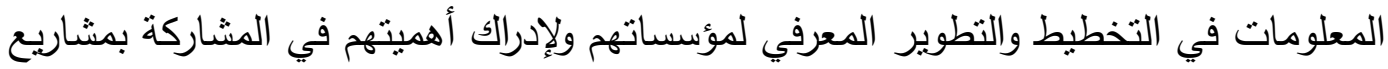
البحث والتطوير و عمليات اتخاذ القرارات و تصميم المؤسسة وصياغة الاحتياجات. ب. سمراء كحلات(؟) ـ تمكين المعرفة في المنظمة الجزائرية:دراسة ميدانية بمكتبات جامعة وصنية باتتة.(رسالة ماجستير)/اشراف نجيبه قموح .جامعة منتوري. كلية العلوم الانسانية و العلوم

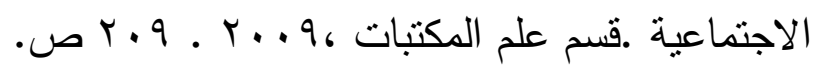

ترمي هذه الدراسة إلى تعميق الفهم حول حقيقة المعرفة وإدارتها التي تتطلب معرفة بإدارة تأخذالفرد والمعرفة الضمنية التي بحوزته الوجهين لعملة التفوق، مع الوقوف على وضعية المنظمةالجزائرية إزاء المعرفة وتمكينها. تم اعتماد الاستبانة كأداة للاراسة وتم توزيعه على عينة الدراسة البالغ عددها الجزائرة أراء المعرفة 177 موظفاً.

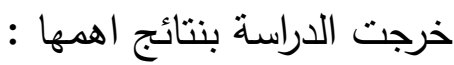
ا. ما يزال الاهتمام بالأمور المادية يطغى على تفكير الأفراد العاملين بالمكتبات محل الدراسة،

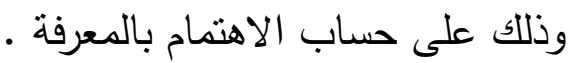
r. أن قلة الوعي بأهمية المعرفة التتظيمية كسبيل لنطوير العمل المكتبي ليس من جانب الأفراد العاملين فقط، بل حتى بالنسبة للقادة الذي يعد همه الأكبر إنجاز العمل وليس محاولة تحسينه ونطويره.

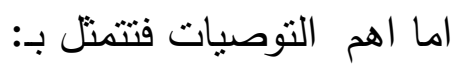

ا.نشر الوعي بأهمية المعرفة والحث على تعلمها وتمكينها والعمل بها من أجل تلمس قيمتها الحقبقية في أوساط المكتبات الجامعية لجامعة باتتة.

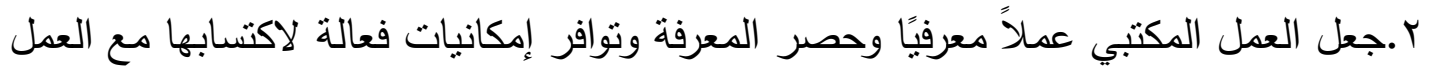
على توليدها وتنثاركها ونقلها ومن ثم توظيفها.

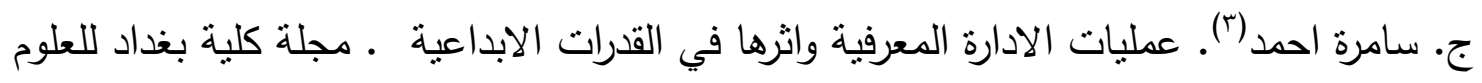

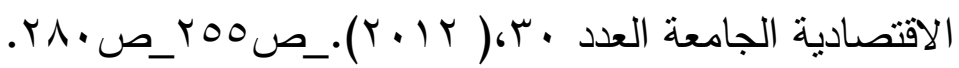
يرمي البحث الى تقديم اطار نظري في الموضوعين القدرات الابداعية والادارة المعرفية على وفق احدث المراجع العلمية في هذا المجال. وتتخيص مستوى عمليات ادارة المعرفة والقدرات الابداعية في عمل المكتبات محل الدراسة. واختيرت عينة عمدية من مديري وامناء المكتبات 
الجامعية في مدينة بغداد وتم استخدام الاستبانة كاداة لجمع المعلومات وبلغ عدد الاستبانة

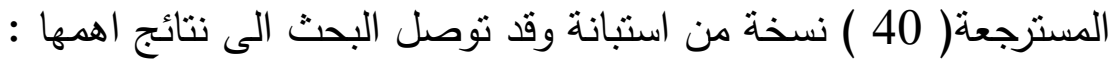

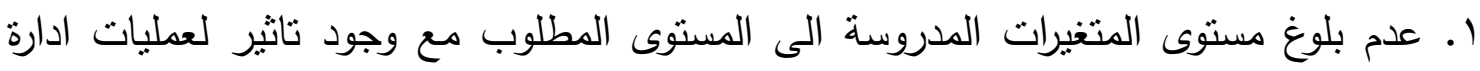

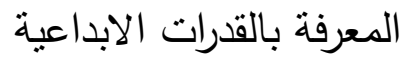

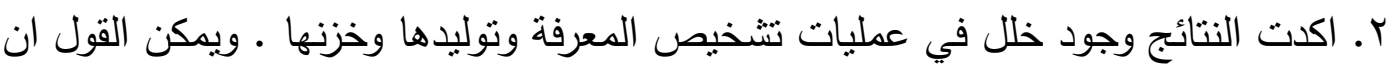
العينة اكدت وجود تحديد لاهداف المعرفة مع قلة عمليات توليدها وان توزيع واستخدام هذه المعرفة القليلة يكون بصورة مقبولة. وخرجت بتوصيات كان ابرزها : 1 . زيادة اهتمام الادارات المسؤولة عن المكتبات الددروسة بالمعرفة وزيادة القدرات المعرفية

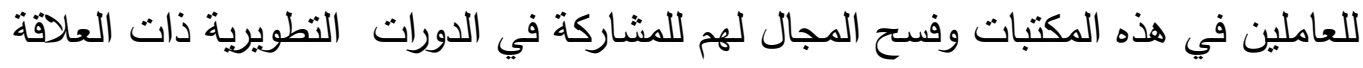
بالمكتبات.

r ـ تشكيل مجموعات عمل للعاملين في المكتبات تقوم بعقد لقاءات دورية وباستخدام وسيلة لوصف الافكاروذلك لتتخيص تواجد المعرفة التي تحتاجها مكتباتهم وتتشيع عمليات الابداع. مكانة الدراسة الحالية من الدراسات السابقة : 1. ركزت الدراسة على الموظفين من هم من حملة الثهادات الجامعية (الدبلوم - الدكتوراة) في حين ركزت الدراسات السابقة على الددراء في الدكتبة .

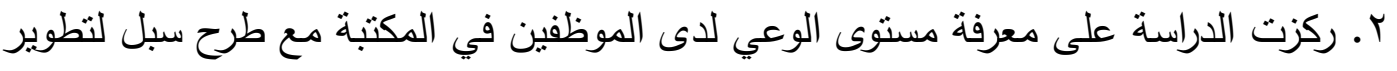

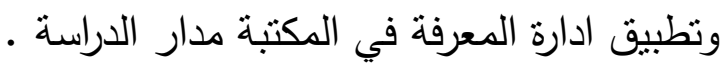

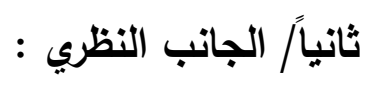

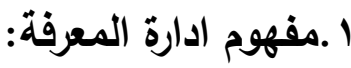

أعطيت لإدارة المعرفة عدة تعريفات لكنها لا تخرج فعليًا عن المعنى والمضمون الذي أجمع معاد عليه جميع من قام بتعريفها ولكن بكلمات مختلفة ونعرض بعض هذه التعريفات: فقد عرفها عبد الدات

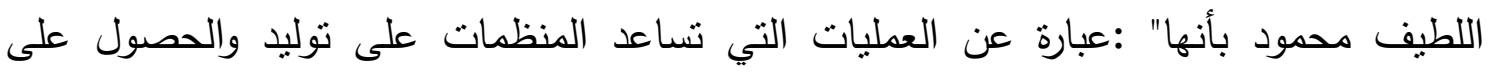
المعرفة ,اختبارها وتتظيمها واستخدامها ونشرها وتحويل المعلومات الهامة والخبرات التي تمتلكها

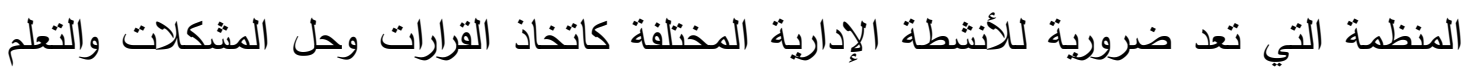
والتخطيط الاستراتيجي".(ع) وعرفها كروس Cross (0) بأنها : "نظام توليد مزدهر وبيئة تعلم من شأنها تثجيع وتوليد كل من المعرفة الثخصية و المعرفة النظمية ,وتجميعها ,واستخدامها

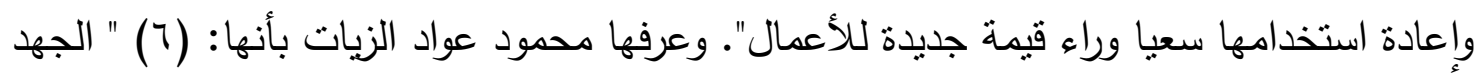


المنظم الواعي الموجه من قبل منظمة أو مؤسسة ما من أجل التقاط وجمع وتصنيف وتتظيم وخزن كافة أنواع المعرفة ذات العلاقة بنشاط نلاك المؤسسة وجعلها جاهزة للتداول والمشاركة بين أفراد

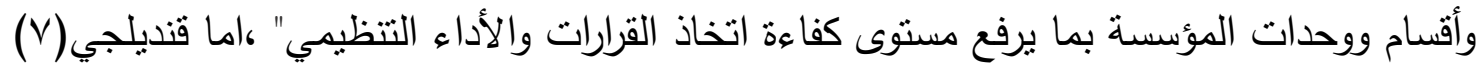
فقد عرفها تعريفاً شاملاً نم استخلصها من عدة تعريفات من مجالات متعددة بأنها المصطلح

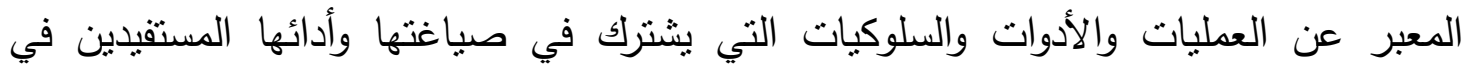

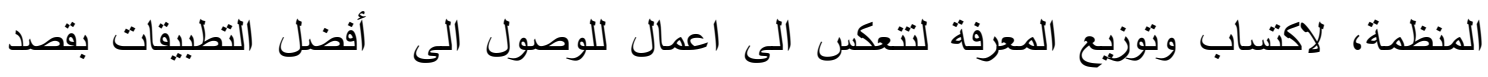

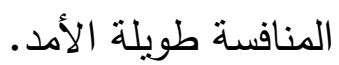

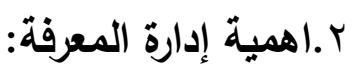

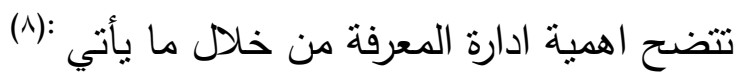
ا ـ تعد إدارة المعرفة فرصة كبيرة للمنظمات لتخفيض التكاليف ورفع موجوداتها الداخلية لتوليد الإيرادات الجديدة r. تعد عملية نظامية تكاملية لتتسيق أنشطة المنظمة المختلفة في اتجاه تحقيق أهدافها r. تعزز قدرة المنظمة للاحتفاظ بالأداء المنظمي المعتمد على الخبرة والمعرفة ،وتحسينه

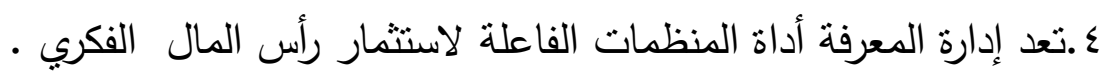

0. تشهم في تحفيز المنظمات لتجديد ذاتها ومواجهة التغيرات البيئية غير المستقرة. 7. تتيح ادارة المعرفة للمنظمة تحديد المعرفة المطلوبة ،وتوثيق المنوافر منها وتطويرها والمشاركة

بها وتطبيقها و تقييمها. V. تعد اداة تحفيز للمنظمات لتشجيع القدرات الابداعية لمواردها البشرية لخلق معرفة جيدة

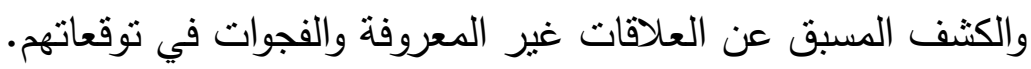

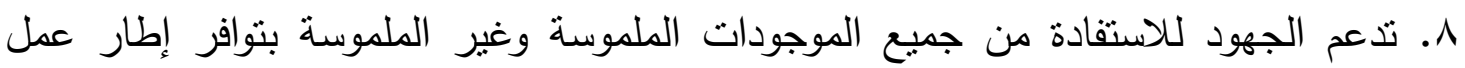

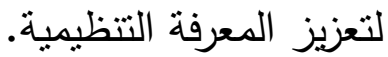
9 . تعد أداة تحفيز للمنظمات لنتجيع القدرات الإبداعية لمواردها البشرية لخلق معرفة جيدة.

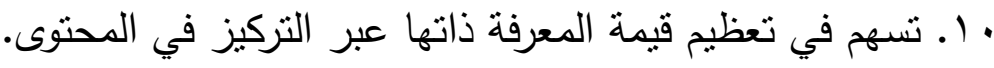

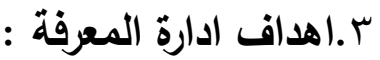

(9):تهدف ادارة المعرفة الى تحقيق الآتي ا ـ أسر المعرفة من مصادرها وخزنها وإعادة استعمالها. r.جذب رأس المال الفكري أكبر لوضع الحلول للمشكلات التي تواجه المنظمة. 
r. خلق البيئة التظيمية التي تشجع كل فرد في المنظمة على المشاركة بالمعرفة لرفع مستوى

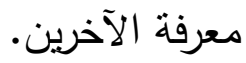

ع ـ تحديد المعرفة الجوهرية وكيفية الحصول عليها وحمايتها. ه. إعادة استخدام المعرفة وتعظيمها.

ا.بناء إمكانات التعلم وإثاعة ثقافة المعرفة والتحفيز لتطويرها والتنافس من خلال الذكاء البشري. V.التأكد من فاعلية تقنيات المنظمة ومن تحويل المعرفة الضمنية الى معرفة ظاهرة وتعظيم العوائد من الملكية الفكرية عبر استخدام الاختراعات و المعرفة التي بحوزتها و المتاجرة بالابتكارات. ^. تحول المنظمات من الاقتصاد التقليدي إلى الاقتصاد العلمي الجديد (اقتصاد المعرفة)، وتعمل كثبكة للأنشطة، حيث تسهم في التحويل نحو الثبكات الاقتصادية الواسعة والتجارة الإلكترونية. 9 ـ انها تعمل على جمع الأفكار الذكية من الميدان، وتسهم في نشر أفضل الممارسات في

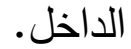
• ا.تهدف إلى الإبداع والتكيف للاضطراب والتعقيد البيئي والتتظيم الذاتي والذكاء والتعلم. 1ا. خلق القيمة للأعمال من خلال التخطيط لها وادارة وتطوير العاملين وادارة الزبائن وتقييم

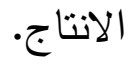

ع ـتطبيق إدارة المعرفة في المكتبات ومراكز المعلومات: إن نجاح المكتبات يعتمد على قدرتها من الاتتفاع والاستفادة من معلومات ومعرفة موظفيها

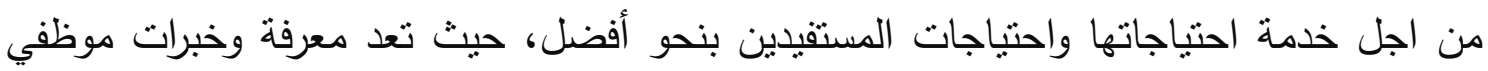

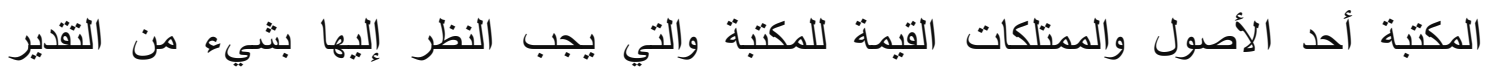

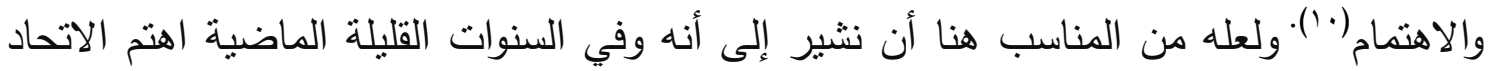

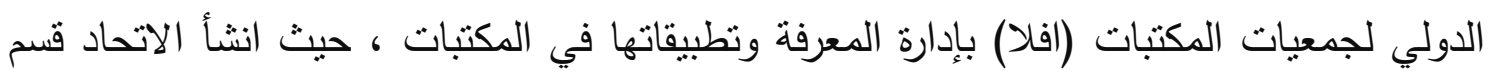

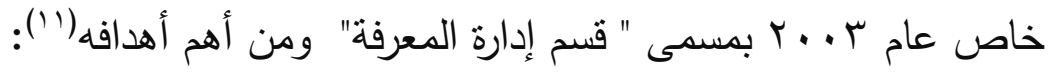
1.دعم ثقافة تطبيق إدارة المعرفة في بيئة الدكتبات والمعلومات. r.عمل إطار دولي للاتصال المهني وفهم طبيعة وأهمية إدارة المعرفة. r. تتبع نطورات إدارة المعرفة والتعريف بتطبيقاتها العملية في المكتبات. ومن المهم جداً أن تكون في المكتبة سياسة لإدارة المعرفة وأن تكون واضحة ومفهومة جيداً من الموظفين، لأن منل هذه السياسة ستوضح للموظفين أي أنواع المعرفة تحتاجها المكتبة لإدارتها 
والمشاركة فيها، كما يفيد ذلك أيضا في أن تقوم المكتبة بخزن واتاحة المعرفة والمعلومات الصحيحة واللازمة لإفادة الموظفين والمكتبة منها (rا'). هـالمتطلبات اللازمة لتطبيق إدارة المعرفة في المكتبات ومراكز المعلومات: يتطلب تطبيق إدارة المعرفة في المكتبات تهيئة بيئة المنظمة للوصول إلى أقصى استفادة

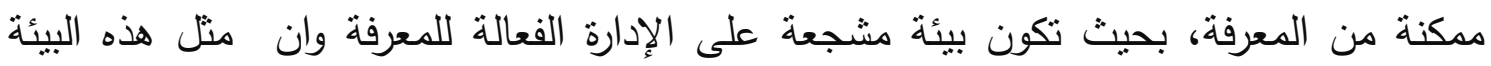
تتطلب توافر العناصر والمنطلبات الآتية:(r) ا.الثقافة التظظيمة: يقصد بها التقافة التي تتجع وتحث على العمل بروح الفريق وتبادل الأفكار

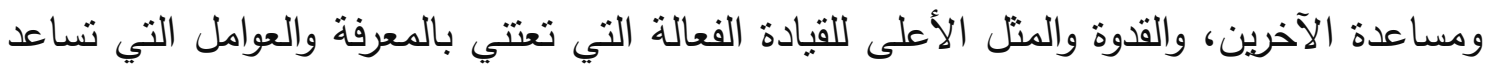

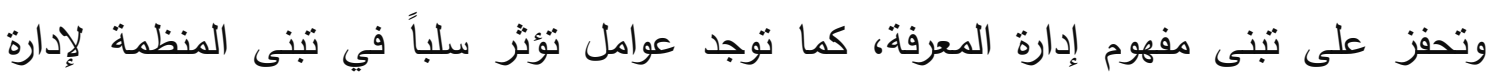

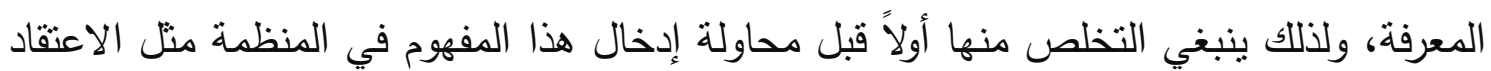
بأن معرفة الأفراد نفسهم لا قيمة لها ، وعدم فهم المعنى الحقيقي لإدارة المعرفة.

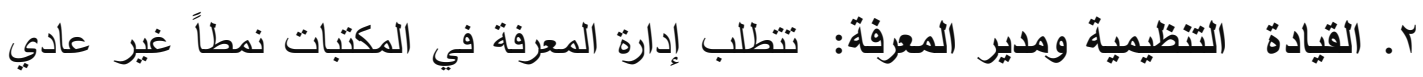
من القيادة يتمكن من قيادة الآخرين، والتأثير فيهم وتحفيزهم والاستفادة من المعرفة الموجودة لتحقيق

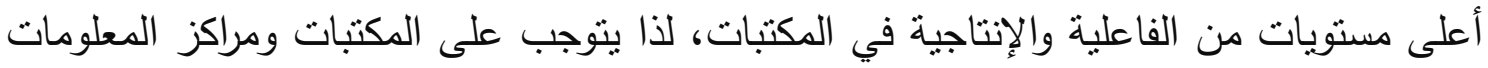

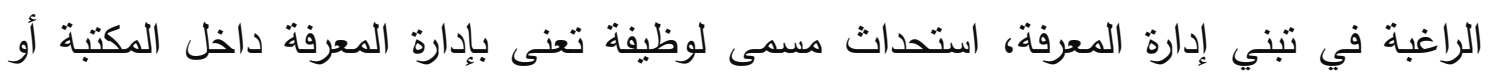

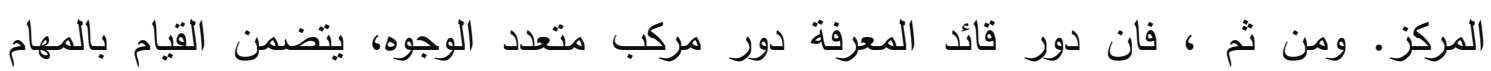

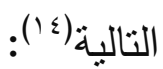

أ. الدفاع عن المعرفة، فالتغيرات طويلة الأمد المتعلقة بالثقافة التنظيمية، وسلوكيات الأفراد المتعلقة بالمعرفة، هي أمر ضروري، وهذه التغيرات تتطلب دفاعا قويا ومستداما. ب. تصميم البنية التحنية للمعرفة وتتفيذها ، ومراقبتها، بما يشمله ذلك من المكتبات، وقواعد المعرفة، وشبكات المعرفة، ومراكز البحوث، والبنية المنظمة المستتدة إلى المعرفة. ج. إدارة العلاقات مع مزودي المعلومات والمعرفة الخارجين (شركات قواعد البيانات أو الثركاء

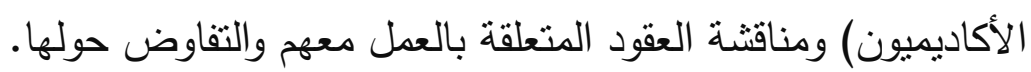
د. قياس وإدارة قيمة المعرفة بواسطة التحليل المالي التقليدي وغيره من أساليب القياس. هـ قيادة تطوير استراتيجة المعرفة، أي تركيز موارد المنظمة في نمط المعرفة الذي تحتاجه

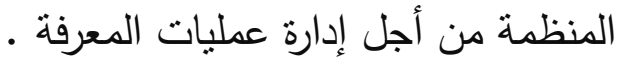
و • بناء نقافة المعرفة في المنظمة. 
r. تقنية المعلومات: إن لتقنية المعلومات دور مهم في تطوير وتتمية المنظمات، من خلال توافر المعلومات المناسبة في الوقت المناسب، ودعم عملية اتخاذ القرار وتحسينها ، وتتشيط حركة فئه

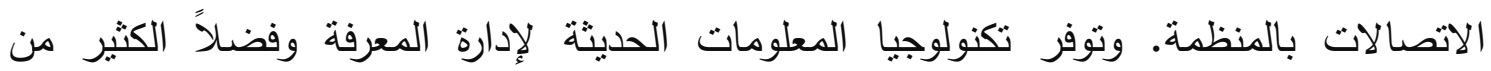

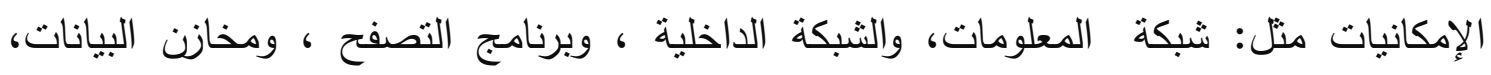

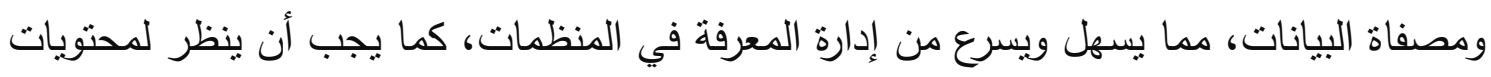

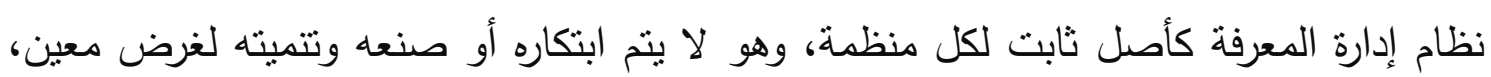

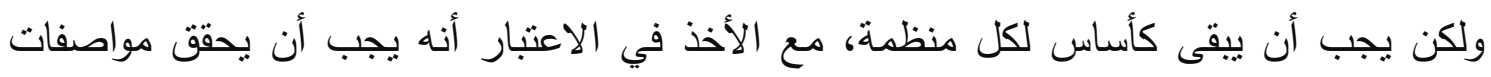

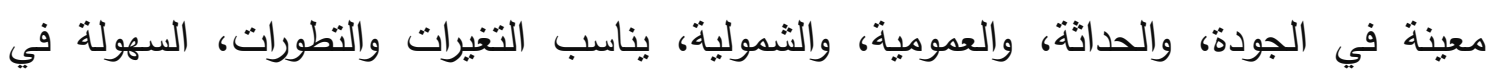

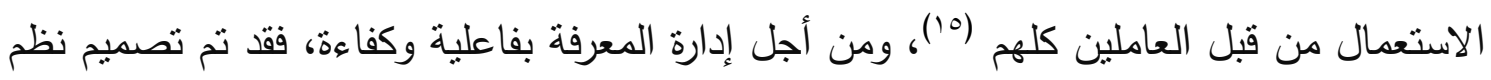

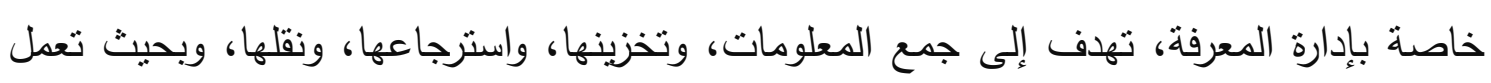
هذه الوظائف مع بعضها بشكل متكامل. ع. القوى البشرية: تمثل القوى البشرية الكادر البشري الذي يقوم بكافة أعمال الككتبة ويعد أحد بلدي

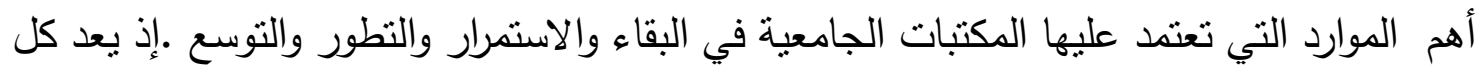
عامل من العاملين في المكتبة عنصر نجاح أو فثل للمكتبة، حيث أن المكتبات الجامعية التي والئي

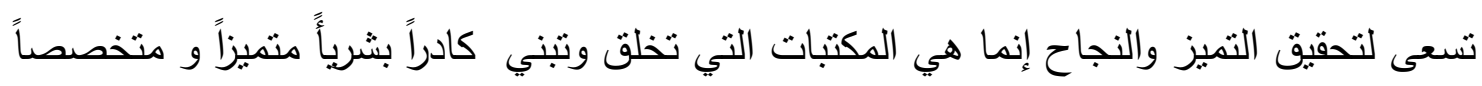

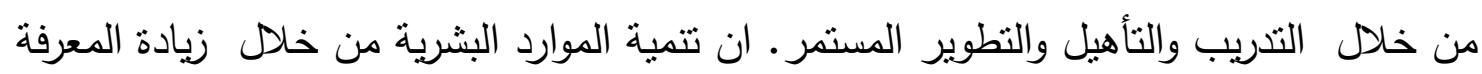

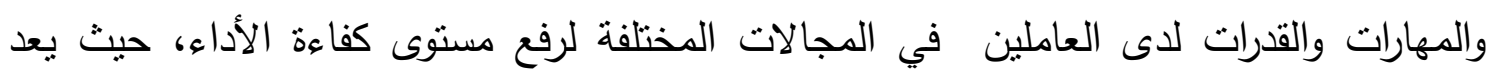

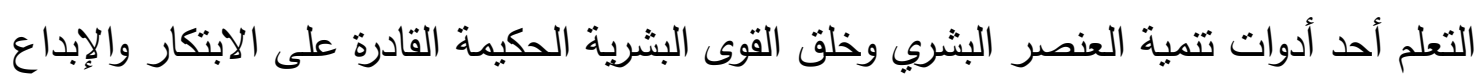
(1). (1) والتأنثير

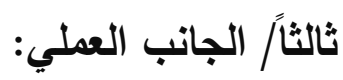
ا.المكتبة المركزية في جامعة السليمانية :

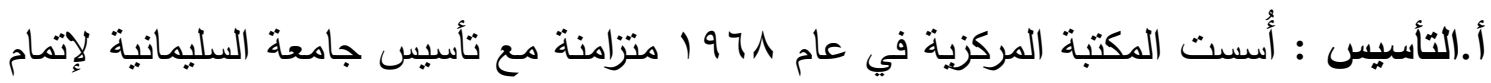

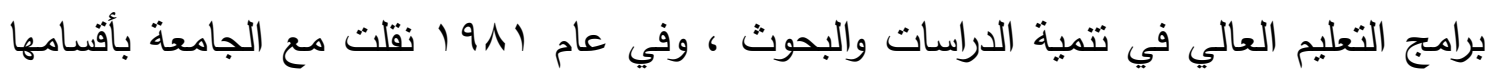

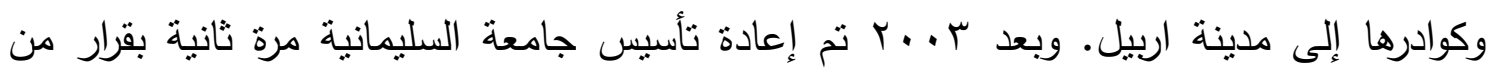

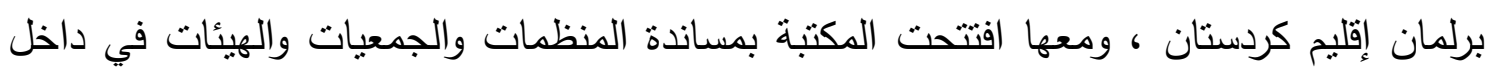

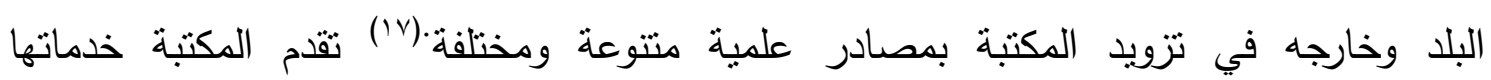
للمستفيدين والباحثين طيلة أيام الأسبوع والمتمثلة بخدمة الاعارة ، خدمة المراجع ،خدمة الانترنت خدمة الاستساخ فضلاً عن المكتبة الافتراضية ( IVSL). 
ب. الملاك الوظيفي: يعمل في المكتبة (9؛) موظف تتفاوت اختصاصاتهم و مؤهلاتهم بين حملة الثهادة الابتدائية وحملة شهادة الدكتوراه"، وكما مبين في الجدول (1) (1). الجدول (1)

يبين التحصيل الدراسي للملاك الوظيفي

\begin{tabular}{|c|c|c|c|}
\hline \multirow[t]{2}{*}{ الاعدادية _ فما ادنى } & \multicolumn{2}{|c|}{ الاختصاص العلمي } & \multirow[t]{2}{*}{ التحصيل الدراسي } \\
\hline & التخصصات الاخرى & علم المعلومات والمكتبات & \\
\hline & 1 & & الاكتوراه \\
\hline & $r$ & $r$ & البكالوريوس \\
\hline & 1. & 10 & الدبلوم \\
\hline$\Lambda$ & & & الاعدادية \\
\hline$r$ & & & المتوسطة \\
\hline$v$ & & & الابتدائية \\
\hline 11 & $1 \leqslant$ & IV & المجموع \\
\hline
\end{tabular}

ج. المجموعة : تضم المكتبة عدداً من الكتب و الدوريات و الرسائل الجامعية و الكتب المرجعية كما مبين في الجدول (Y)، اذ تم تتظيم المجموعة على وفق نظام تصنيف ديوي العشري بالاعتماد على موسوعة التصنيف العشري لمحمد عوض العايدي ... T اللى جانب تعديل نظام تصنيف

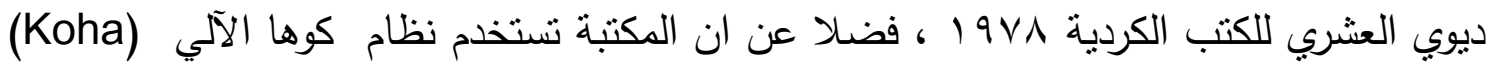

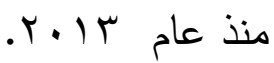

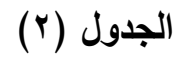

يبين أنواع مصادر المعومات الموجودة في المكتبة المركزية ـ جامعة السليمانية

\begin{tabular}{|c|c|c|c|c|c|c|}
\hline العدد & لغات اخرى & الفارسية & الانكليزية & اللغة الكردية & اللغة العربية & أنواع مصادر المعلومات \\
\hline 00101 & YVY. & - & $|V \cdot r|$ & IVO.Y & 189.0 & الكتب \\
\hline TYY.V & $\leqslant 0$. & 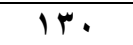 & $0 \wedge 4 \wedge$ & TाT & 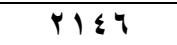 & المجلات و الصحف \\
\hline 70.5 & 9 & - & $r r \leqslant 0$ & $V Y \leqslant$ & $Y \leqslant Y T$ & الرسائل الجامعية \\
\hline $11 \ldots$ & - & - & - & $11 \ldots$ & - & الأقر اص لمكتنزة \\
\hline V0799 & - & - & - & - & - & المجموع \\
\hline
\end{tabular}

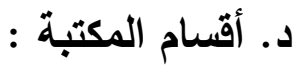

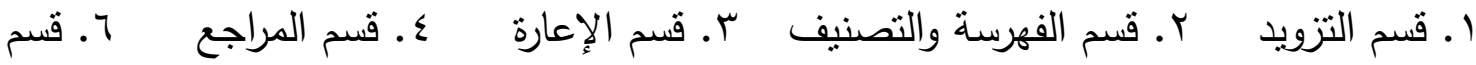
الانترنت V. قسم الرسائل الجامعية ^. قسم المواد السمعية والبصرية9. قسم التجليد والصيانة

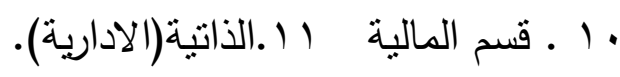


r ـ تحليل أسئلة الاستبانة:

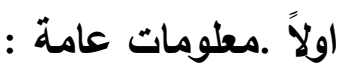

تم توزيع مجتمع الدراسة حسب ( الجنس ، الثهادة ، التخصص العلمي ،عدد سنوات الخدمة

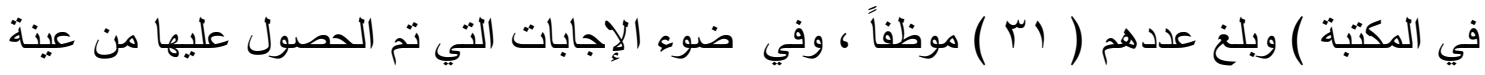

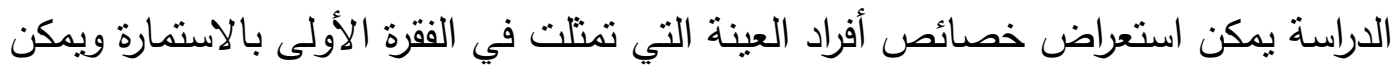

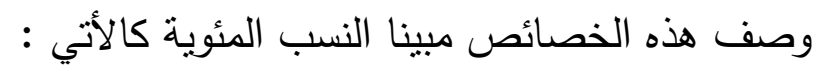

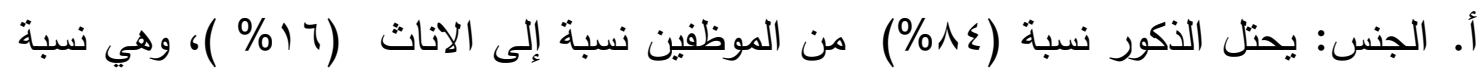
متفاوتة.وكما مبين في الجدول (ع).

الجدول (๕) (؛)

يبين جنس الموظفين الموجودة في المكتبة المركزية ـ جامعة السليمانية

\begin{tabular}{|c|c|c|}
\hline النسبة المئوية & العدد & جنس الموظف \\
\hline$\%$ & $r q$ & ذكر \\
\hline$\% 17$ & 0 & انثى \\
\hline$\% 1 \ldots$ & $r 1$ & المجموع \\
\hline
\end{tabular}

ب. الثهادةالعلمية: يتضح من خلال الاستبانة ان ب موظفاً يحملون شهادة الدبلوم ويشكلون

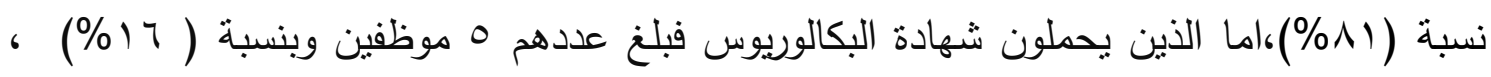
في حين بلغ عدد الذين يحملون شهادة الدكتوراه موظف واحد بدرجة مدير المكتبة. الجدول (0)

يبين الشهادة العلمية للعاملين بالمكتبة

\begin{tabular}{|c|c|c|}
\hline النسبة المئوية & 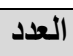 & الثهادة العلمية \\
\hline$\%^{\wedge 1}$ & ro & الدبلوم \\
\hline$\% 14$ & 0 & البكالوريوس \\
\hline$\%^{\mu}$ & 1 & الاكتوراه \\
\hline$\% 1 \ldots$ & $m$ & المجموع \\
\hline
\end{tabular}

ج. الاختصاص العلمي : يتضح من الجدول ادناه ان نسبة(00\%) هم من المتخصصين في علم

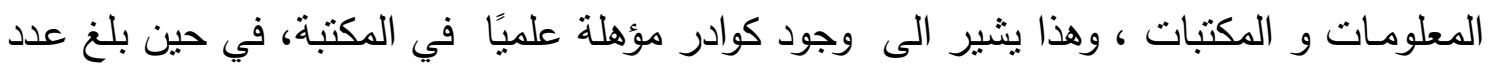
الموظفين في التخصصات الاخرى (0؛ ٪).

الجدول (7)

يبين الاختصاص العلمي للموظفين بالمكتبة

\begin{tabular}{|c|c|c|}
\hline النسبة المئوية & العلد العدا & الاختصاص \\
\hline$\% 00$ & IV & علم المطلومات و المكتبات \\
\hline$\% \leqslant 0$ & $1 \varepsilon$ & التخصصات لاخرى \\
\hline$\% 1 \ldots$ & $r 1$ & 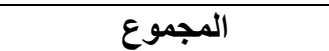 \\
\hline
\end{tabular}


د. سنوات الخدمة في المكتبة: يتضح من نتائج استبانة الموظفين في المكتبة اللذين تتراوح سنوات

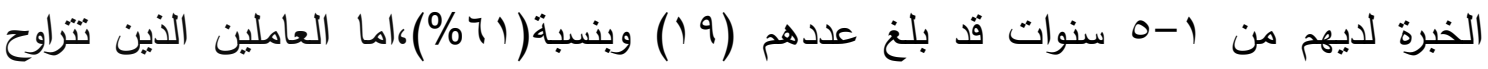

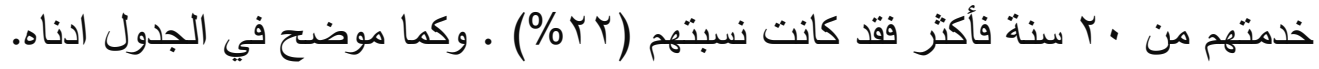

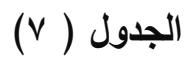

يبين سنوات الخدمة للموظقين في المكتبة

\begin{tabular}{|c|c|c|}
\hline النسبة المئوية & العدد & سنوات الخدمة \\
\hline$\% 71$ & 19 & $0-1$ \\
\hline$\% \mathrm{~V}$ & $r$ & $1 \cdot-7$ \\
\hline$\% \mathrm{~V}$ & $r$ & 10.11 \\
\hline$\% r$ & 1 & $r \cdot-17$ \\
\hline$\%$ \%r & $V$ & • . ـ فما اكثر \\
\hline$\%$ & 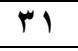 & المجموع \\
\hline
\end{tabular}

ثانياً/ ادراك العاملين بالمكتبة لمفهوم ادارة المعرفة:

يبين الجدول (^) أن مستوى إدراك العاملين لادارة المعرفة في المكتبة المركزية بجامعة السليمانية يتركز في (انها ادارة تهتم بالعنصر البشري وتؤمن بأنه مهم لتحقيق التميز وتطوير خدمات المكتبة) وبنسبة (7 (1\%)،تليها العبارة التي تؤكد انها ( اسلوب حديث لتبادل الاراء والافكار والعمل الجماعي) وبنسبة (0 \%). في حين حصلت العبارتين (فلسفة ادارية تهدف الى تغيير في تفكير العاملين نحو الادارة وفي تفكير الادارة نحو العاملين) و(عملية نوليد المعرفة واكتسابها وتخزينها واستخدامها لتحقيق اهداف المكتبة) على اقل نسبة بواقع (9\%).

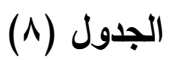

ادراك العاملين لمفهوم إدارة المعرفة

\begin{tabular}{|c|c|c|}
\hline النسبة المئوية النية & التكرار & ادراك العاملين بالمكتبة لمفهوم ادارة المعرفة \\
\hline$\% 17$ & rq & ادارة تهتم بالعنصر البثري وتؤمن بأته مهم لتحقيق التميز وتطوير خدمات المكتبة \\
\hline$\% 10$ & rV & اسلوب اداري حديث لتبادل الاراء والافكار والعمل الجماعي \\
\hline$\% 1 \leq$ & Yq & إدارة المعرفة سمة للإدارة الحليثة \\
\hline$\%$ /T & ro & توجه اداري جديد يهذف الى ارضاء المستفيدين بالدرجة الاولى \\
\hline$\%{ }^{\prime r}$ & rr & يتم النظر إلى إدارة المعرفة على أنها إدارة المطلومات. \\
\hline$\%$ & Y1 & الدمج بين المعرفة وخبرة العاملين والتقنيات المتوفرة في المكتبة \\
\hline$\% 9$ & 17 & فلعفة ادارية تهذف الى تغييرفي تفكير العاملين نحو الادارة وفي تفكير الادارة نحو \\
\hline$\% 9$ & 17 & عملية توليد المعرفة واكتسابها وتخزينها واستخذامها لتحقيق اهداف المكتبة \\
\hline$\% 1 \ldots$ & IAr & 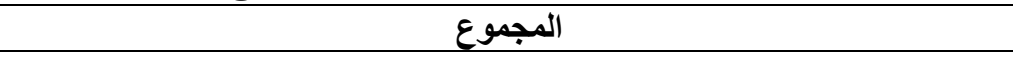 \\
\hline
\end{tabular}

يتبين من الجدول (9) أن أبرز المجالات المتعلقة بواقع تطبيق إدارة المعرفة في المكتبة تتمثل في( ان المكتبة تتيح للعاملين فرص التعاون والعمل بروح الفريق) وبنسبة (9 (\%) ، تليها 
الفقرة المتعلقة بـ ( يتوفر للمكتبة موقع على شبكة الانترنت كوسيلة معرفية و التواصل بين المستقيدين والعاملين ) اذ بلغت نسبتها (7 (\%)، في حين ان مجال التطبيق الخاص بالفقرة (تحرص إدارة المكتبة إلى تطوير العاملين من خلال الدورات التثريبية ) و الفقرة(تعمل ادارة المكتبة على حصر وتوثيق معارف وخبرات العاملين بحيث نسهم في حل المشكلات التي تواجهها المكتبة وجعلها مناحة للاستخدام ) حصلتا على اقل نسبة (^\%). (9) الجدول (9)

تطبيق ادارة المعرفة

\begin{tabular}{|c|c|c|}
\hline المئويبة & التكرار & مجالات تطبيق ادارة المعرفة في المكتبة من خلال : \\
\hline$\% 19$ & $r \varepsilon$ & تتيح المكتبة للعاملين فرص التعاون والعمل بروح الفريق \\
\hline$\% 17$ & $r \cdot$ & يتوفر للمكتبة موقع على شبكة الانترنت كوسيلة معرفية و التواصل بين المستفيدين والعاملين \\
\hline$\% 10$ & 19 & تحرص المكتبة على استقطاب العاملين المؤهلين للحصول على مايمتلكونه من المعرفة \\
\hline$\% 10$ & 19 & توفير ميزانية مناسبة لدعم مشاريع إدارة المعرفة \\
\hline$\% 1$ & 14 & تثشارك إدارة المكتبة العاملين في اتخاذ القرارات وتحديد التوجهات والخطط المستقبلية \\
\hline$\% 9$ & 11 & تدعم الادارة الأفكار الإبداعية وتعتني بالكفاءات \\
\hline$\% \wedge$ & $1 \cdot$ & 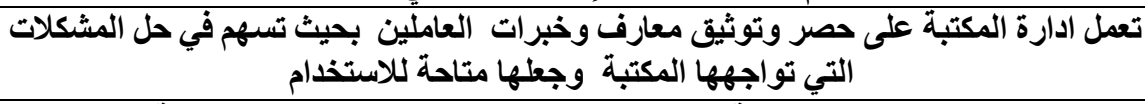 \\
\hline$\% \wedge$ & 1. & تحرص إدارة المكتبة إلى تطوير العاملين من خلال الدورات التدريبية \\
\hline$\% 1 \ldots$ & $1 \% 7$ & 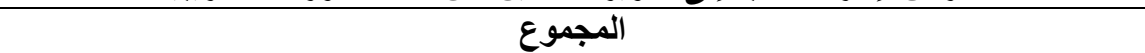 \\
\hline
\end{tabular}

رابعاً/ المعوقات التي تواجه تطبيق ادارة المعرفة: من الجدول رقم (• () يتضح وجود بعض المعوقات التي نواجه نطبيق ادارة المعرفة في المكتبة من وجهة نظر العاملين عينة الدراسة وكان ابرزها (عدم توافر وحدة تتظيمية تعني بالإثراف على إدارة المعرفة) وبنسبة (V V\%)، يليها (ضعف اهتمام الادارة بتتمية معارف ومهارات العاملين) اذ شكلت نسبة (7 (1\%).اذ ان عدم وجود جهة مسؤولة تعد من اهم المعوقات التي تحول دون تطبيق ادارة المعرفة بدرجة كبيرة.

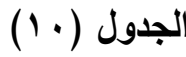

المعوقات التي تواجه تطبيق ادارة المعرفة

\begin{tabular}{|c|c|c|}
\hline النسبة المئوية & التكرار & المعـوقــات \\
\hline$\%$ IV & ro & عدم وجود وحدة تنظيمية تعني بالإشر اف على إدارة المعرفة \\
\hline$\% 17$ & YT & ضعف اهتمام الادارة بتنمية معارف ومهارات العاملين \\
\hline$\% 10$ & Y1 & انخفاض مستوى مشاركة العاملين في صنع القرارات \\
\hline$\% \mathbf{O}^{\mathrm{T}}$ & 19 & شيوع ثقافة احتكار المعرفة \\
\hline$\%$ & 11 & تجاهل المكتبة للافكار والحلول التي يقترحها العاملون \\
\hline$\% 11$ & 17 & ضعف الاستفادة من الوسائل التكنولوجية في جمع وتبادل الخبرة بين العاملين \\
\hline$\% 9$ & iT & ندرة العاملين المختصين في إدارة المعرفة \\
\hline$\% \mathrm{~V}$ & 1. & ضعف تكيف و تأقلم العاملين مع بيئة العمل \\
\hline$\% 1 \ldots$ & $1 \leqslant 0$ & 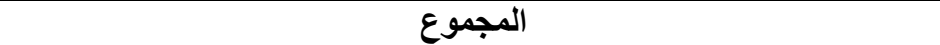 \\
\hline
\end{tabular}


خامساً سبل تطوير تطبيق ادارة المعرفة في المكتبة :

يتضح من الجدول (1) أن أبرز سبل تطوير تطبيق إدارة المعرفة في المكتبة المركزية بجامعة السليمانية تتمنل في: ( العمل على تطوير الكادر المكتبي من خلال تفعيل التدريب)

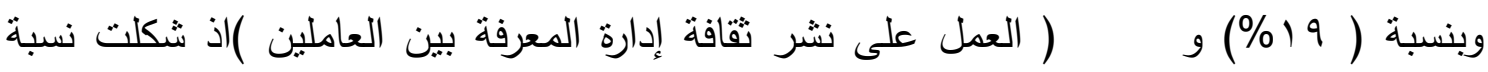

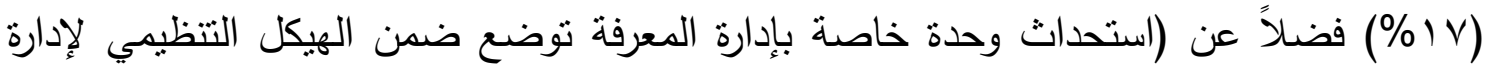
المكتبة) وبنسبة ( 10 \%) ، ومما سبق يتضح ان نجاح تطبيق إدارة المعرفة في المكتبة يتطلب

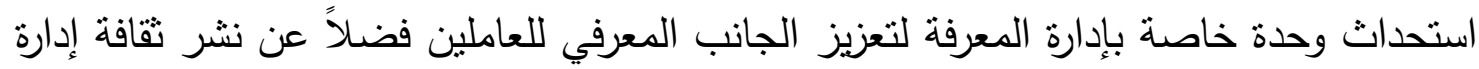
المعرفة بين العاملين الأمر الذي يدفعهم نحو الإدبداع في أعمالهم. (1) (الجدول

سبل تطوير تطبيق ادارة المعرفة

\begin{tabular}{|c|c|c|}
\hline 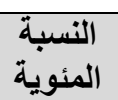 & التكرار & سبل تطوير تطبيق ادارة المعرفة \\
\hline$\% 19$ & $r$. & العمل على تطوير الكادر المكتبي من خلال تفعيل التدريب \\
\hline$\% 1 \mathrm{~V}$ & rV & استحداث وحدة خاصة بإدارة المعرفة توضع ضمن الهيكل التنظيمي لإدارة المكتبة \\
\hline$\% 10$ & ro & نشر ثقافة إدارة المعرفة بين العاملين \\
\hline$\%{ }^{2 \mu}$ & r. & 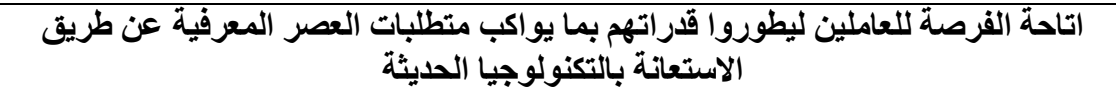 \\
\hline$\%$ & 11 & تفوض إدارة المكتبة بعض المهام للعاملين بما يساهم في رفع مستوى الخبرة و المعرفة لديهر \\
\hline$\% 9$ & 10 & التواصل بين إدارة المكتبة و العاملين لتفهم وجهات النظروتبادل الافكار \\
\hline$\% \wedge$ & ir & توفير مستوى من الثقة التفاهم بين العاملين في بيئة العمل بالمكتبة \\
\hline$\% \mathrm{~V}$ & 11 & تثشارك إدارة المكتبة العاملين في اتخاذ القرارات وتحديد التوجهات والخطط المستقبلية \\
\hline$\% 1 \ldots$ & $10 \mathrm{~V}$ & 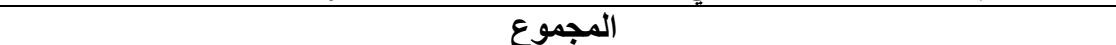 \\
\hline
\end{tabular}

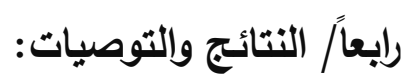
أ. أ. النتائج:

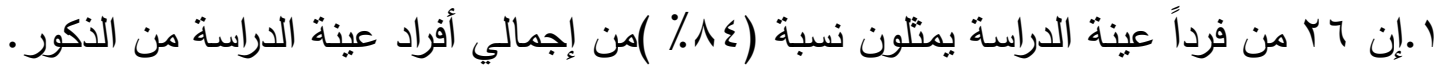

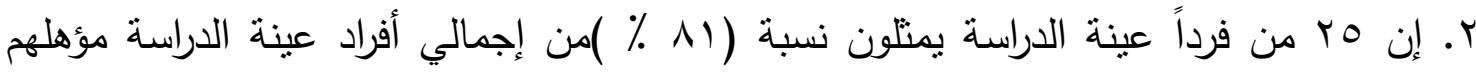
العلمي( الدبلوم) ،وهم الأغلبية من أفراد عينة الدراسة.

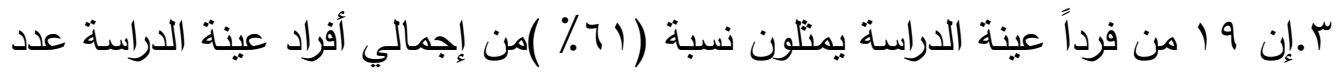
سنوات خبرتهم (1- 1 سنة ) وهم الأغلبية من أفراد عينة الدراسة.

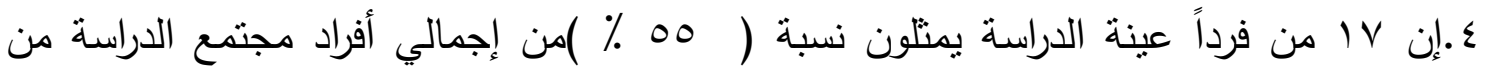
المتخصصين في علم المعلومات و المكتبات، وهم الأغلبية من أفراد مجتمع الدراسة.

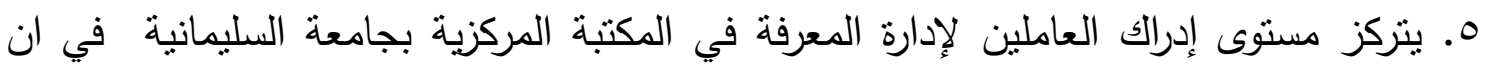

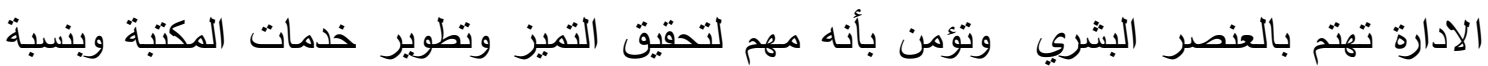


(7 (1\%)،تليها العبارة التي تؤكد انها اسلوب حديث لتبادل الاراء والافكار والعمل الجماعي وبنسبة (0 (1\%).مما يدل على الاستفادة من الخبرات عن طريق العمل بروح الفريق.

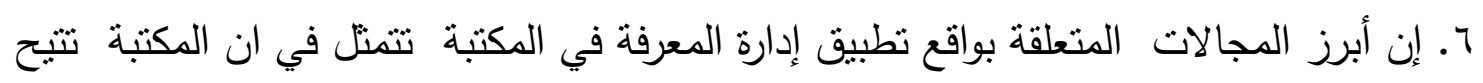

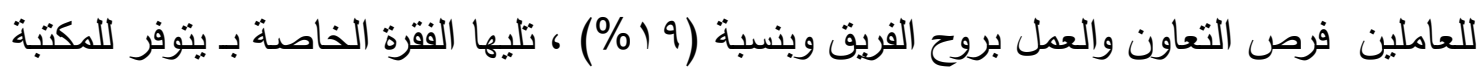

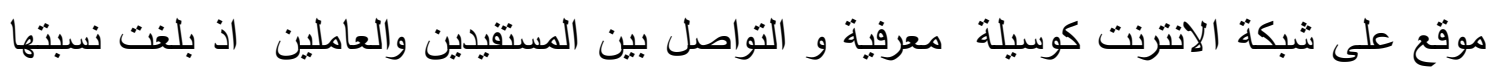
.$(\% 17)$ V. عدم توافر جهة مسؤولة تعنى بالإثراف على إدارة المعرفة وتتفيذ عملياتها اذ شكلت نسبة . $(\% \backslash v)$ 1. ضعف اهتمام الادارة بتمية معارف ومهارات العاملين المعوقات التي تواجه نطبيق ادارة المعرفة في المكتبة اذ شكلت بنسبة (1 (1\%). ب. التوصيات: ا ـانثاء وحدة خاصة بإدارة المعرفة توضع ضمن الهيكل التنظيمي للمكتبة تكون مهنها تنظيم

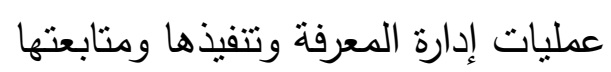

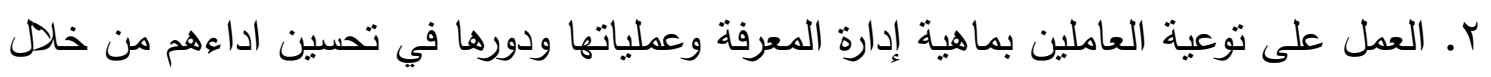
عقد الندوات والمحاضرات وورش العمل والدورات التدريبية.

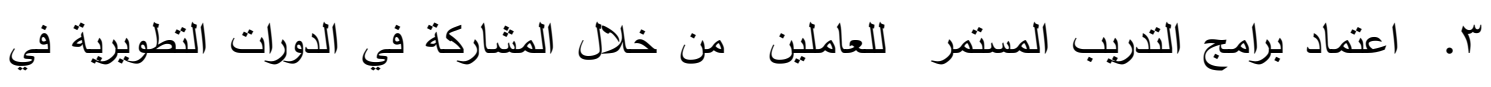
اختصاصيي المكتبات و الحاسبات.

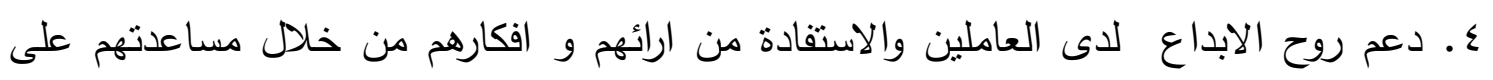

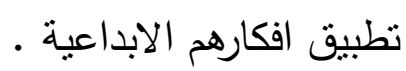
هـاستقطاب العاملين المتخصصين في علم المكتبات و المعلومات للعمل في المكتبة بما يعزز الرصيد المعرفي للمكتبة . المعابن 4.السماح للعاملين بالمشاركة في اتخاذ القرارات ولاسيما الكفاءات وذوبي الخبرة من المتخصصين مكتبياً. V Vلق مستوى من الثقة و التفاهم بين العاملين في بيئة العمل بالمكتبة. 


\section{المصادر (حسب ورودها في البحث):}

ا .نعيمة حسن جبر رزوقي. روئة مستقبلية لدور اختصاصيي المعلومات في إدارة المعرفة مجلة مكتبة الملك فهد

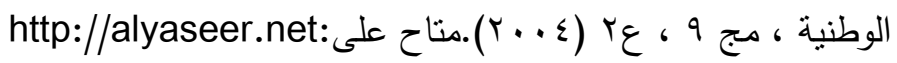
r.سمراء كحلات ـ تمكين المعرفة في المنظمة الجزائرية: دراسة ميدانية بمكتبات جامعة باتتة.(رسالة ماجستير)

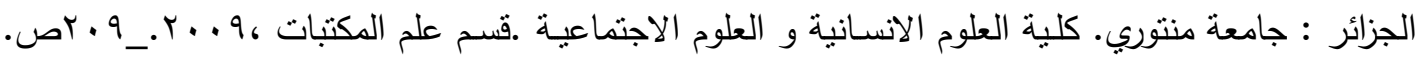

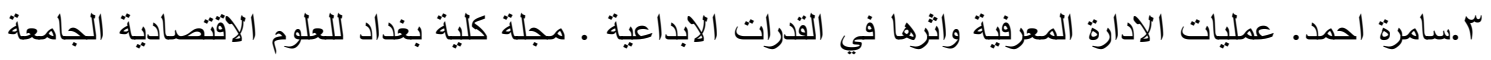

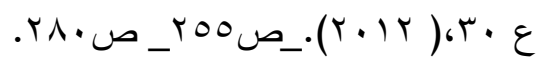

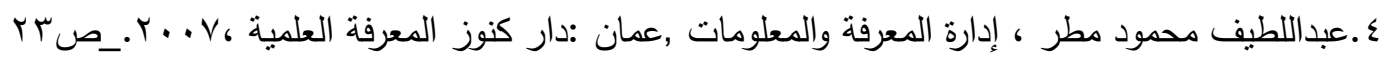

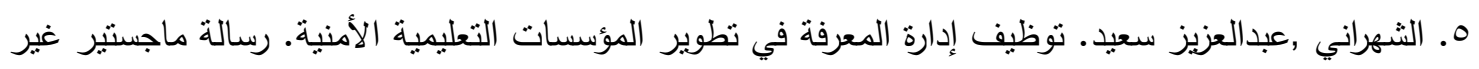

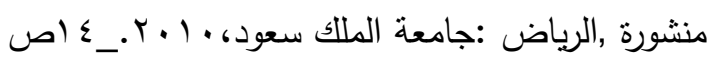

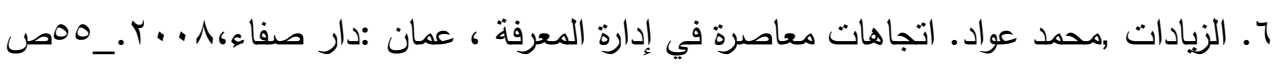

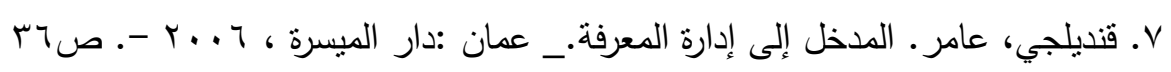

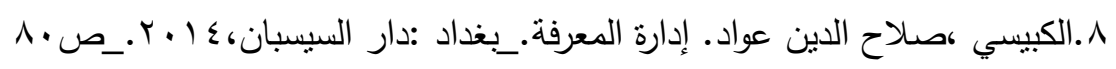

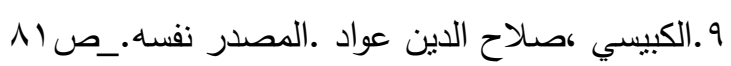
• ا. الضويحي ،فهد بن عبداله . إدارة المعرفة في المكتبات ومراكز المعلومات : النظرية والنطبيق.-

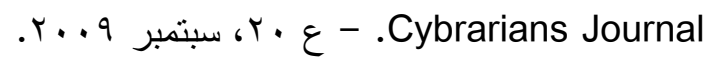
http://www.journal.cybrarians.info مناح على

11. Knowledge Management Section. IFLA Home Page. (Accessed 13-05-08). Available at: (http://www.ifla.org/VII/s47/index.htm)

r ا.الضويحي،فهد بن عبد الله.المصدر السابق

با ا.عبد الوهاب، سمير محمد. منطلبات نطبيق إدارة المعرفة في المدن العربية: دراسة حالة مدينة القاهرة. في :

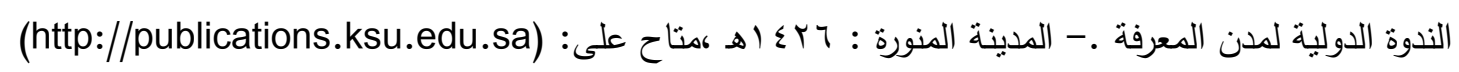

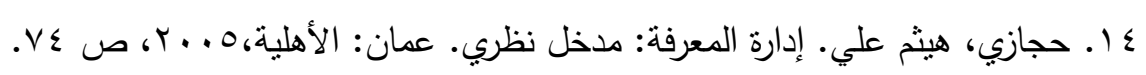
10 ـ • عبد الوهاب، سمير محمد. المصدر السابق. متاح على: (http://publications.ksu.edu.sa) 17

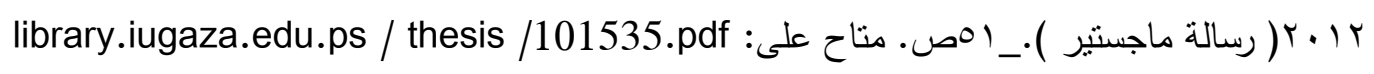
Http: //c-library.univsul.net . IV 